\title{
سيميائية العتبات النصية في شعر / فاضل مزيز فرمان
}

\author{
م. كريم عجيل الهاشمي \\ جامعة واسط/ كلية التربية \\ |ل|l|l|l|
}

تسعى در استتا الى الوصول للمجالات البحثية التي تكثف عن سيميائية العتبات في البناء النصي للشاعر( فاضل

عزيز فرمان) بوصفها أنظمة نصية تسهم بشكل أو بآخر في الإشارة لشيء ما، عبر نركيز الدراسة في فاعلية العتبات

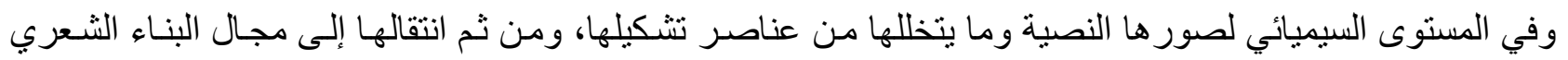

الذي تتداخل فيه مجالات متعددة لإتتاج دلالتها الثعرية، و اغلب النقاد يطلقون تسمية العتبات الموازية على هذه العتبات

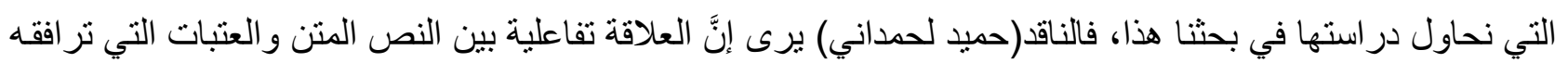
و على رأيه"إن مصطلح النصوص الموازية (Pasatextesles) الذي وضعه جيرار جينت بتضمن إثـارة تُبعد إلى نى حد مـا فكرة التفاعل بين العتبات و النصـوص المرتبطة بها، فالموازاة تحمل معنى الانفصـال، أب أنها تقصسي فكرة الاتصال، ولذلك فاستعمالنا للمصطلح لا ينبغي أن يؤخذ بحرفيته، فالعلاقة القائمـة بين العتبات والنصوص التي تنتمسي إليها هي على الأصح علاقة تفاعلية، من دون أن ينفي ذلك وجود استقلالية نسبية لكل جانب عن الآخر "(') لذا سنحاول در اسة هذه العتبات من جهة تفاعلها مع النص المتن للوقوف على فاعليتها.

\begin{tabular}{|c|c|c|c|c|c|c|c|c|c|}
\hline Semiotic & text & thresholds & in & the & poetry & of & Fadhil & Aziz & $\begin{array}{l}\text { Farman } \\
\text {--Hashimi }\end{array}$ \\
\hline Karim & & & & Ajee & & & & & al-Hash \\
\hline ollege & of & Educ & & & University & & & & Wa \\
\hline
\end{tabular}

\section{Abstract}

Our study seeks to access the research areas that reveal semiotic thresholds in building the text of the poet (Fadhil Aziz Farman) as text systems in some way contribute to the signal of something, through the study, the concentration of the effectiveness of the thresholds in the semiotic level images text and punctuated by elements of composition, and then it moves to the construction poetic field in which multiple areas overlap to produce the poetic significance, and most critics have called parallel thresholds on these thresholds, which we are trying to study in this research, critic (Hamid Hamdani) believes that the interactive relationship between the text tenderloin and thresholds accompanied on his mind, "the parallel texts term (Pasatextesles) developed by Gerard Gent includes a reference away to some extent the idea of the interaction between the thresholds and texts associated with them, the parallel carries the meaning of separation, that is, finding the idea of contact, so the using of the term should not be taken literally. The relationship between the thresholds and texts it belongs to is rather an interactive relationship, without denying the presence of relative independence of each side about the other "(1), so we will try to study these thresholds from its interaction with the text tenderloin to determine the effectiveness.

\section{أولا :عتبة العنوان}

عتبة العنوان هي من تمنح النص ـ مهما كان جنسه ــ شكله، عبر تسميته والخروج به من الفضاء غير المعلوم

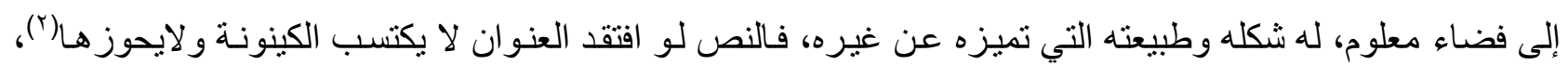


و هو بهذا يعد من ابرز العلامات النصية السيميائية التي تتطلب الوقوف عندها مليا لفهمها وتحليلها وصو لا إلى ما تعني وتحمل من دلالة.

إن الثـاعر يؤسس بفعل كل عتبة من عتبـات مجاميعه الثـعرية الى مقاصد في التلقي النصـي ، قاصداً التفاعل بينه وبين متلقيه من خلال نصسِهِه ، بشرط أنْ لا تكون هذه العتبات مشتتة لمبنـاه الجوهري الذي يقصده، فهو يحاول ان

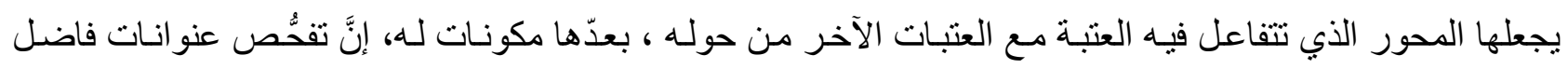

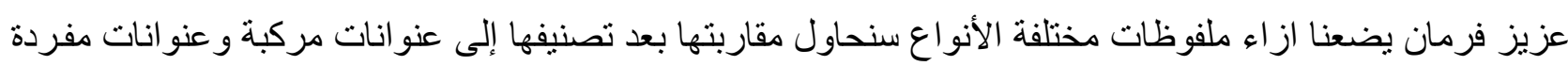
ونحاول معرفة مدى انسجامها في حال انتظامها في نسق معين

\section{العندان لغة واصطالاوها:}

من خلال البحث عن مـادة (عنـا ، وعنن) في المعـاجم العربيـة تبين انهما يعنيان الأثر، وكلما استدللت بشيء تظهره على غيره فهو عنوان له و عنتت الكتاب واعنتته أبي عرضته له، قال اللحياني: عننت الكتاب و عنتته إذا عنونته، ويقال للرجل الذي يعرض ولا يصدح، قد جعل كذا وكذا عنواناءلحاجته، قـال ابن البري : والعنوان هو الأثر(ب) في حين يذهب الدكتور محمد فكري الجزار إلى ان لكل واحد منهما دلالة تختلف عن الأخرى على الرغم من انه يتبنى

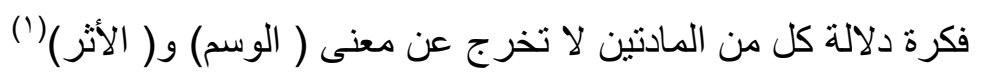

يكاد يتطابق المعنى المعجمي مع المعنى الاصطلاحي لمفهوم العنوان بشكله الواسع إذ يعرف ليو هوك العنوان

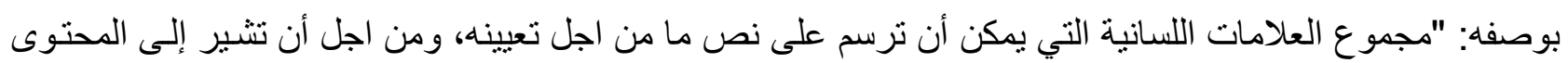
العام، وأيضاء من اجل جذب القارئ"(؟)، فالعنوان على وفق هذا المفهوم، بنية أساسية من بنى النص المختلفة التي لا يمكن تجاوز ها لفهم كنهه ومعناه، فهو العتبة الأولى التي من خلالها يتم الولوج إلى عتبات النص الأخرى. و العنوان بوصفه عتبة يمثل "أولى بؤر الإشعاع التي تؤسس السمت الدلالي.... انه بنية لغوية مشفرة تستبطن التجربـة... انـه بنية

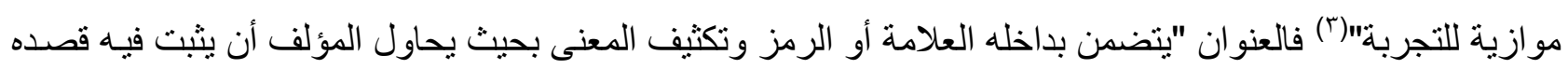
برمته أي انه النواة التي خاط المؤلف عليها نسيج النص و هذه النواة لا تكون مكتملة ولو بتذييل عنوان فرعي فهي تأتي كتساؤل يجيب عنه النص"(؛) وسنحاول دراسة العناوين و أنوعها للوقوف على أهميتها كعتبة قرائية.

\section{أنواع الهناوينغ:}

تتعدد العنو انات كثير ا بالثكل الذي يجعل منها تتشظى وتتفرع إلى رئيسية وفرعية من دون أن تفقد أهميتها من

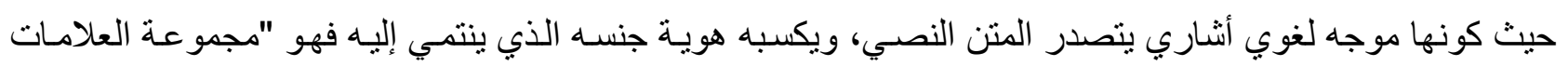

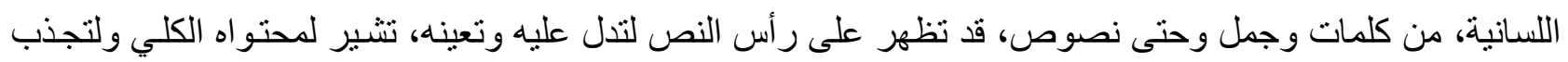
جمهوره المستهدف"(0) ؛ لذا نجد أن اختيار العنوان للنص جزء من إبداع الأديب بـان يجعله ضمن منظومـة المساقات

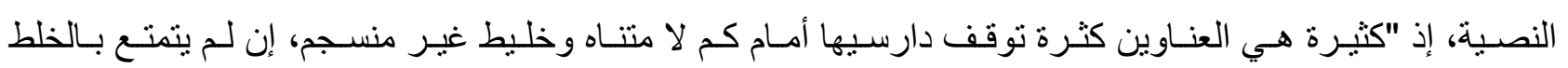
و الاضطر اب حتى ليبدو أن تنظيم هذه الظـاهرة أمر من قبيل المستحيل في الوقت الذي تتمتع فيه الأعمـال بقابلية للتصنيف و التوزيع ومسن ثم التنظيم"(Y)، فـالعنوان بهذا يمثل صـورة على المستوى الدلالي قد تـرتبط بمـا بعدها فـ"الصورة أيّاً كان شكلها هي الأقوى، من حيث مفاعيلها النفسية والأيديولوجية.. وهي من جهة أولى الأكثر إثارة 
و إغر اء، من حيث كينونتها الحسبة"(7) وكلما أحسن المبدع اختيار العنوان أصبحت دلالتها كصورة خصبة فـ"ميزة الصـورة الخصبة أنها تسـطيع أن تشـع في كل اتجـاه وأن تسـح للك باستكناه المزيد من المعـاني كلمـا أوغلت معها

بحسك" (1).

وقد ذهب النقاد مذاهب شتى في تحديد أنواع العنوانات في النصوص الأدبية تبعا لطبيعة فهمه لمضمونه، فمنهم

من قسمه على نوعين من خلال تحديد طبيعة العنوان و علاقته بالمتن النصي فوجهه إلى سياقي وآخر غير سياقي ف "العنوان السياقي يكون وحدة مـع العمل على المستوى السيميائي، ويملك وظيفة مر ادفة للتأويل عامـة ، أمـا "العنوان

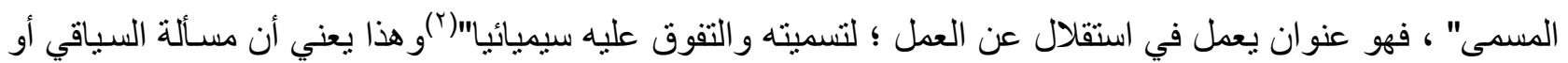
غيره محكومة بالتلاؤم و الانسجام بين المتن والعنوان إذ "تعود مسـألة الانسجام في العنوان باعتباره نصـا مستقلا إلى خضو عها لمنطق لغوي محدد، فالكاتب ينطلق من رؤيسة معينة في صياغة عنو انـه ورسم ملامحسه التي تضفي عليه صفة من التو افق مع النص الموما إليه"(") ويذهب باحث آخر إلى تقسيمه إلى ملفوظونوع آخر أطلق عليه غير ملحوظ،

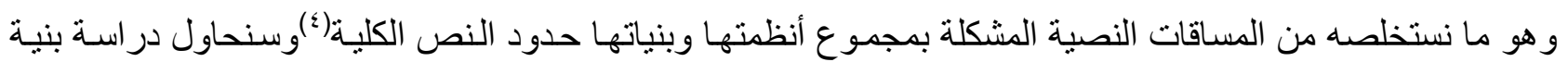
العنوان و أنو اعه في شعر فاضل عزيز فرمان من خلال ملاحظة محمود عبد الوهـاب في تقسيماته للعنوان إلى مفرد ومركب(؟)،ققد حاول الثشاعر فاضل عزيز فرمان الإفادة من فاعلية العنونـة في الصعود بمجـال خلق المتعـة والجمال للمتلقي من خلال التتويعات المختلفة لبنيات عنو اناته التي توزعت بشكل واسع في منجزه الثعري الكبير.

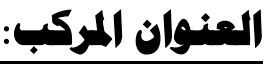

سنحاول دراسة هذا النوع من العنوانات بشكل تتساوى فيه العنوانات الرئيسة التي تتصدر المجموعات الثـعرية

و العنو انات الفرعية التي تشكل مجموع نصوصه الثعرية للوقوف على مستويات الجمال ومقاربة دلالتها السيميائية. مجموعة فرمان التي طبعت سنة م ـ . ب (عزف منفرد على وثر الأربعين) في مطبعة اتحاد الكتاب العرب تعد احد تمثلات العنو ان المركب، وقد اختير هذا العنوان من بين عنو انات المجموعة البالغ عددها (Yr) نصا شعريا لتكون موجها أثشاريا لمتن المجموعة الثعرية بالكامل، وقد تلازمت الملفوظات المشكلة له بشكل يشي بعدم إمكانيـة انفصـالها عن بعضـها بعض خشية أفتقادهـا دلالتهـا التي امتدت إلى داخل منت المجموعـة ممـا يشير إلى تو افقها نو افقـا دلاليـا، فالعنوانات الأخرى ضمن هذه المجموعة لا تبتعد عن مضمون العزف والموسيقى فالنص الأول منها ( دوزنـة أولى) و هو احد مصطلحات الموسيقى وأدو اتها التي تتتجها، وقد تكررت هذه الدوزنة أربع مرات على مدار أربعة نصوص، ونص (موال) و هو لا يخرج عن حدود الموسيقى ونص (القصيدة الر اقصـة) كانت ضمن نصوص المجموعـة وهو رقص بتطلب الموسيقى أيضا، بمعنى ان هناك ثمة رابط خفي يربط نصوص المجمو عة، فبنية العنو ان بوصفها بنية موازية للمتن نمثل عنو ان مركب يخص شخصا واحدا فالعزف وصف بالمفرد ( عزف مفرد) والآلة التي يعزف عليها تنماز بوتر مفرد ( وتر الأربعين) و هذا يمثل مرحلة عمريـة توصف بالنضـج لحساسيتها، فالثناعر يحساكي نفسـه بعد وصوله لهذه المرحلة من العمر .وكانت قصيدة ( نزف مفرد) ضمن هذه المجموعة يحاكي العزف المفرد فالثـاعر

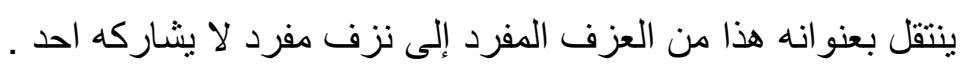




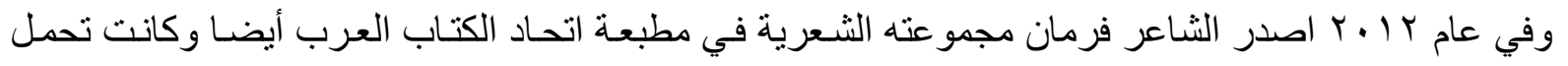
عنو انا مركبا تركيبا اسناديا ( دموع الجمل ) و هو يعني دموعه، وهو ما كثَف عنه من حيث لا يشعر في نسختي التي

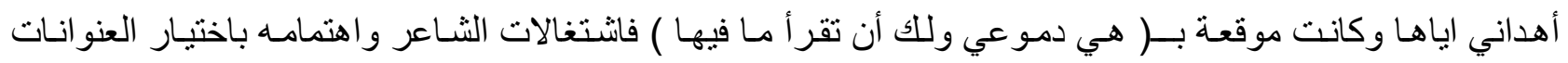
الملائمة لان تتصدر متنه النصي كانت تتسم بالحساسية والدقة حتى تستو عب طروحات المجمو عة وتتسجم معها بشكل لا يجعله غريبا عنها لذا كان العنوان المركب يشـل مسـاحة وحيز اكبر من مسـاحة المجموعة الكلية، وتكاد تشكل مهيمنة اسلوبية في مجمل مجاميعه الثعرية، فهذا المنحى يخدمه في تجسيد دلالة التي يبحث عن السبل التي تجسدها. المجموعة الأخرى التي أصدر ها الثاعر عام ـ ا ــ عن المؤسسة الوطنية للتنمية والتطور كانت تحمل عنوانـا مركبا أيضا ( منى تتفتح الوردة) هو تساؤل تجيب عنه نصوص المجموعة بحكم عنو انها محكوم بسياق النص الموازي اعني عتبة العنوان إذ إن العنوان له "وظائف شكلية وجمالية ودلالية تعد مدخلا لنص كبير كثير ا مـا يشبهونه بالجسد هن

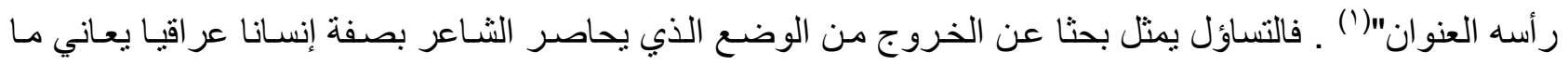
يعانيه أبناء هذا الوطن. ولو نحينا العنو انات المركبة للمجاميع الثعرية وانتقلنا إلى العنوانـات الفرعية المركبة من داخل هذه المجاميع وحاولنا مقاربتها وفلك علاماتها السيميائية نجد ان العنوانـات الفرعيـة لا تقل قيمـة عن العنوانات الرئيسـة التي تتصدر المجمو عة، إذ ثمة وظائف تلازم العنوان بمختلف جزئياته وتتعباته لذا فان له "قيمة سيميولوجية أو اثارية تفيد وصف لهف

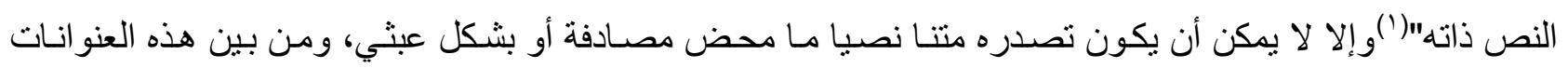
المركبة ( أول الأسئلة ) ضمن مجمو عته عزف منفرد على وتر الأربعين وهو عنوان يمثل ملفوظ لغوي يثكل جزءا لها من البنيـة النصية يؤدي دور الترابط بين النص ومتلقيـه فالمبدع "يعنون لهم النص باعتبـار هم المنخرطين فعـلا في

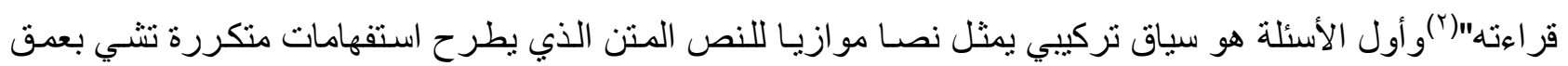
معاناة الذات الثاعرة فيقول في نصه ترى أي باب

سنفتحه

في سجون الشحارير في دمنا

يا ترى

أي

باب وكل المفاتيح

تحتار في فتح اقفالنا

والسؤال

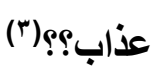

تشتغل اغلب نصوص الثـاعر فرمـان على تسـاؤلات كبرى تتطلب و عي فكري للإجابـة عنها كما في النص المتقدم الذي يفتتحه باستفهام ينبني على فكرة الصر اع الفكري النفسي نتيجة للتقابلات و الاضطر ابات التي يعيثـها الفرد 


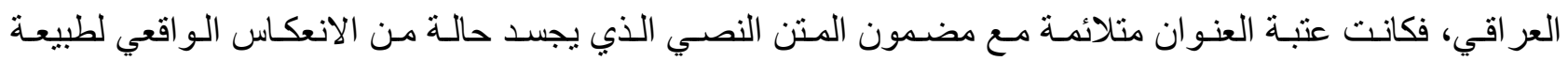
المجتمع، فالعنوان يثير حالة من الدهثة للبحث عن أجوبة ملائمسة لمقتضى مـا مطلوب عبر حالة الانفتاح اللا محدود لحركة الثخصية الرئيسة التي أثث لها الثـاعر بما يتماثـى وحالـة الظلام والبؤس التي يعيشها، إذ شكل النص بمعية العنوان حالة من العرض القصصي تسهم بمجملها بتعزيز الدلالة التي يسعى إليها الثاعر عبر اشتغالاته هذه. ولو تتبعنا العناوين الفرعية المركبة الأخرى ضمن المجموعة نفسها نجدها تنتظم في بنية دلاليـة كبرى لا تخرج عن إطار ها العام الذي يسير باتجاه العودة إلى النفس والبوح بالأوجاع والآلام الذي يسيطر عليه كما في نص ( القصيدة

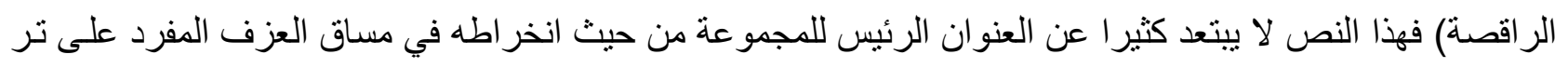
الأربعين، فهي تمسكت بدلالة المجموعة الكبرى و انضمامها إلى ثيمة الحزن التي تسيطر على شكل المجموعة الثـعرية بالكامل فهي قصيدة تجسد مقاصد الثشاعر من خلال اصطفافها في عنو ان مركب من ملفوظين اثثين فيقول فيها:

\section{حين يكون الرقص عنيفا يشتبك الحابل بالنابل حين يكون الرقص عنيفا}

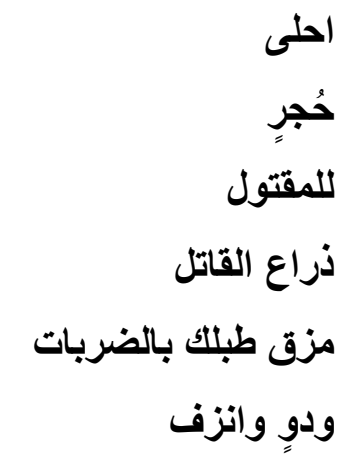

مثل الثريان المبتور( ) مدون

ان العنوان الرئيس لهذا المتن النصي الذي ينضوي تحت عنوان المجموعة بكاملها يجعل المتلقي يعيش وحدة سردية متكاملة لا يفصلها فاصل، فالعنوان المركب لها ( القصيدة الر اقصة) هو بنية موازية للمنن الذي يندرج تحته من

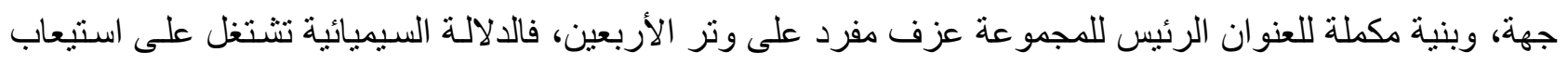

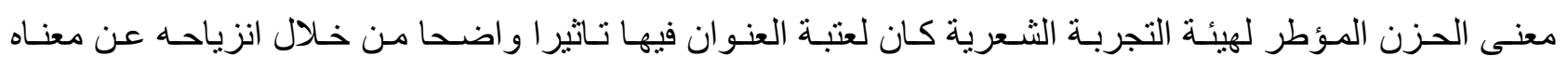
الظاهر اتي ودخوله في تتـابك بنائي سياقي عبر جزئياته النافذة لجدار التلقي وتبلور هـا دلاليا ضمن مكوناتـه التشكيلية

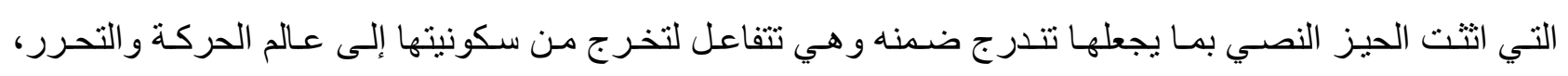
فالقصيدة الرقصة تشي بعبثية الحركة غير المدروسـة لارتباطها بالحركية وفقدان السكون الذي ينتهي بـالخروج عن المألوف وتقبل ما يصدر عنها. و هذا التنازم في المنن مع العنوان الذي يتصدر المجموعة فضلا عن انسجامه مـع عنوانه الفرعي المركب ظل سمة ملازمة لنصوص الثاعر فرمان ولمجاميعه الثعرية الثلاث، فنص دموع الجمل هو متن نصي يندرج ضمن بنى 
المجموعة تصدر أيضا متنا نصيا فرعيا، بمعنى انه أخذه من العنوان الرئيس ولم يخرج عن إطساره العام ومن خلاله يكثف الثناعر عن حزنه الذي حاولنا الكثف عن دلالته السيميائية فيقول فيه:

$$
\begin{aligned}
& \text { من ترى... يعرفهُ } \\
& \text { من يسأل؟ } \\
& \text { جملا صار على التل.... } \\
& \text { ف...... } \\
& \text { فوق التل هذا الجمل } \\
& \text { السرى طال } \\
& \text { وكل الارض صحراء }
\end{aligned}
$$

\section{وقد اضناه ما جاء به العقل (')}

ثمة تعالق بنائي واضح بين تركيبية العنوان وسيميائيته التي لا تخرج عن حدود الحزن وتحمله، إذ ترتبط لفظة الجمل بهاتين الدلالتين فكل منهمـا علامـة سيميائية على قوة التحمل التي ترتبط بالجمل و لا تفارقه، فالثـاعر حاول الإفادة من هذه الدلالة فوضعها عتبة عنو انية ممهدة للاخول إلى المتن النصي، لعلمه بفاعليتها كعتبة قر ائية تكون بمثابـة أداة إجر ائيسة مسـاندة للوصـول إلى هدف النص، وهذا التعـالق بين العنو انين بحسب جنيت حركة شـارحة في بنيتهـ الظاهرة لبنية أعمق؛ لان العناوين الداخلية بشكلها السطحي الظاهري هي عناوين تتزاح عن ظاهريتها البسيطة لتتجهـ

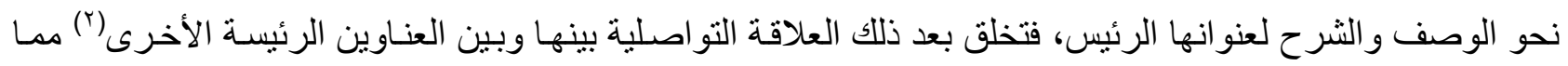
يسهم في ديمومة التو اصل القرائي بين المبدع و المتلقي للوصول إلى إنتاج نص يحقق ما خطط لله.

\section{العنوان المغرد:}

العنوان المفرد هو النوع الثاني من بين التقسيمات لأنواع العناوين التي تتصدر المتون النصية، فالعنـاوين من دون أدنى شك تمثل بكونها "مفاتيح نرشد إلى الأبواب التي يمكن الدخول منها إلى العالم الذي تعنون"(") بمعنى أنها موجها قر ائيا لمنلقي النص وقد ركزت السيميائية كمجال نقدي على عتبـة العنوان لإيمـان المشتغلين بهذا الحقل من الدر اسات النقدية بأنه نص موازٍ، وعتبة قر اءة يمكن أن تشتغل على المفاتيح الأساسية للنص الداخلي"(') المتلقي يكون بحاجة إلى معاينة فاحصة تعينه على فهم النص لمجار اته وفق هيكله الذي تنتظم فيه ويتصدر ها عنوان مرشد بربطه بالمتن، من هنا تتولد الوظائف التي سنحاول تتبعها للوقوف على أهميتها، وقد وردت عناوين كثيرة ضمن المجموعات الثعرية الثنلاث تحمل ملفوظو احد ويكون عنو انا لمتن نصي، يوصف في بعض الأحيان بأنه بنية مستقلة فهو يسـاوي

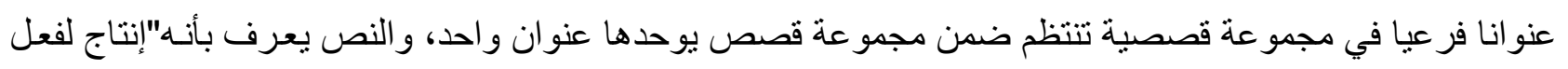

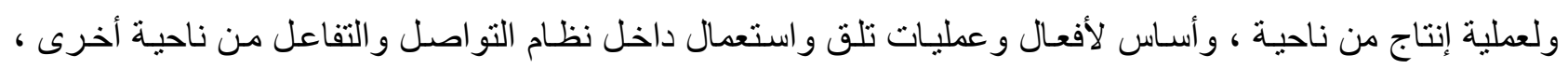

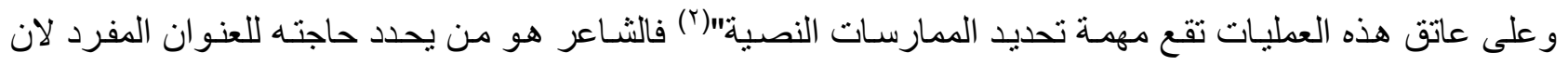
يتصدر نصه ويكون موازيا له ويتصف هذا العنوان بالقدرة على التفاعل بينه وبين المنن لخلق المتعة والحضور . 
وسنحاول تسليط الضـوء على العنوانـات المفردة التي وردت في منجز الثـاعر فرمـان الثـعري للوقوف على فاعليته التي يضفيها على النص الذي يتصدره و علاقته بنصوص المجموعة التي يرد ضمنهاهومن بين هذه العنو انـات

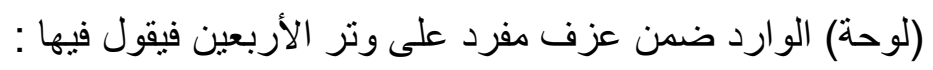

طيور بلا اجنحة

وسموات بلا طيور !!

\section{يا لها من لوحة شوهاء تلكا التي على الارض \\ يا لها من لوحة ناقصة تلك التي في الافاق الرسام الذي رسم السماء لم يكن نفسه \\ الرسام الذي رسم الارض(")}

تتضح فاعلية العنوان الفرعي لنص ( لوحة ) بشكل تدريجي مع التقدم بقر اءة النص و الدخول في عو الم المسـاق الذي يؤطر ها، فلفظة اللوحة لها دلالة سيميائية تدفع بالمتلقي إلى البحث عن كنه هذه اللوحة لتحديد موضو عها فتتفاعل مكونـات المنت النصسي المتمثلة بألفاظ مستوحاة من عو الم فن الرسم ( الرسـام الذي رسم السماء....) هي ملفوظـات

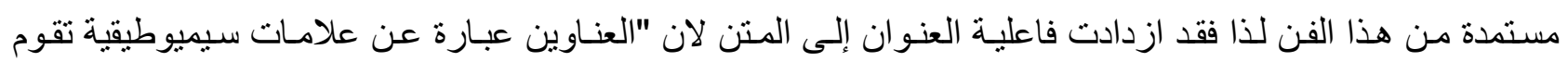
بوظيفة الاحتو اء لمدلول النص، كما تؤدي وظيفة تناصية إذا كان العنوان يحيل على نص خارجي يتتاسل معه، ويتلاقح شكلا وفكر ا"(') وبما ان العنوان هو نص موازٍ للنص المتن فهو يحمل طاقة سيميائية فاعلـة تحمل بين جنباتها دلالات مختلفة فانـه يتفاعل بشكل أو بـآخر مـع النص المتن لكون طبيعته تتصف بالمشـاركة التـي تكون بحاجـة إلى معرفـة شفر اتها وكيفة استشفاف الدلالة منها. و على هذه الثناكلة من التوظيف التفاعلي المتعالق جاءت اغلب العنوانـات الفرعية لنصوص المجاميع الثـعرية للشاعر فاضل عزيز فرمان التي بالإمكان مسك دلالاتها السيميائية عبر هذه الحرفنـة العالية من التوظيف، فلو تناولنـا

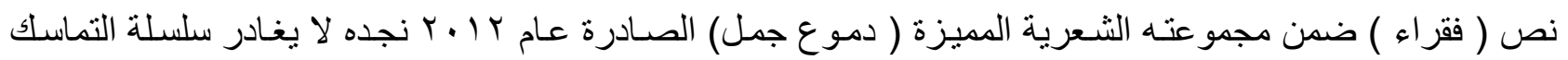
المفرط لعناوين المجموعة الفرعية مع عنو انها الرئيس من جهة ومنونها النصية من جهة أخرى فدموع الجمل صبره و الفقر اء احد هذه الدموع التي يذرفها الجمل، فيقول في نص فقر اء:

$$
\begin{aligned}
& \text { على غير ما يملك الآخرون } \\
& \text { يملك الفقراء } \\
& \text { قليلا من المال والأمنيات } \\
& \text { فرصا }
\end{aligned}
$$




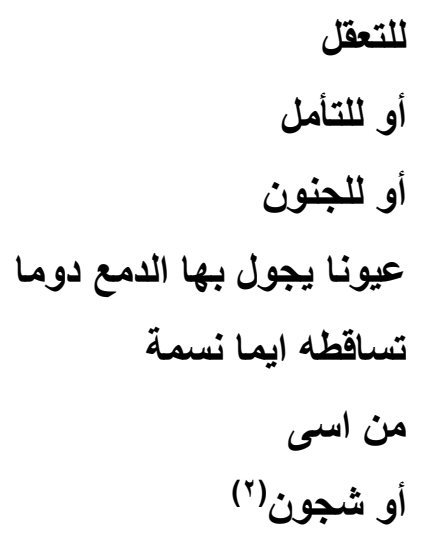

لا ريب ان سيرورة القر اءة السيميائية لهذا المتن النصسي تتعـالق مـع العتبـة العنوانيـة التي تتصدره (فقر اء)إذ ان"النصوص الموازية إنما هي في جميع الأحوال خطاب تابع بمعنى أنه غالبا يكون في خدمة النص الأساسي" ('). فلو حجبت هذه العتبة و أتيح لمتلق ما قر أته وطلب منه حين إتمامها وضع عنوان (فقراء ) من دون شك لان كل الملفوظات التي شكلت المتن النصي لا تخرج عن أطسار الفقراء بمعنى ان الثـاعر نجح إلى حد بعيد من خلق نظام تفاعلي بين المتن النصي و العتبة العنو انية المتصدرة له التي أضفت حالة من الجو النفسي المشـارك لفعل الفقراء ومـا يملكون من أمنيات وأمو ال قليلة، فكانت اشتغالات العنوان المفرد تختصر بشكل مكثف معانـاة طبقة من المجتمع بشكل مكثف صور ها بطريقة در امية فاعلة .

\section{ثانيا عتبة الغلاف}

قد لا يختلف اثنـان على ان عتبـة الغلاف هي العتبـة البنائيسة الأولى التي تواجـه المتلقي لذا عمد الثـعراء إلىى السعي لاختيار الأغلفة التي تحيل دلالتها المرجعية على ثيمة المجموعة الثعرية وتكون جز ءا منها ومكملة لها، للإفادة منهـا في خلق نـوع من المشـاركة التفاعليـة بين النص وبين المتلقي من خـلال اختبـار الألوان و الرسومات الر امزة وطريقة توظيفها وتموضع كل ما يحبط بـالعنوان الرئيس الذي يتوسطها، إذ تناط بـالغلاف مهمة تسـاوي النص تتمثل بكونها العلامة السيميائية الثارحه للنص، ومتى ما كان هنالك تو افق بين غلاف الكتاب ومضمونه كانت سبيلا لنجاحه وشد لذهانية متلقيه. ولغرض معرفة أهمية هذه العتبة سنحاول استنطاق أغلفة المجاميع الثـعرية الثناث للثـاعر فاضل عزيز فرمان للوقوف على مدى إفادته منها.

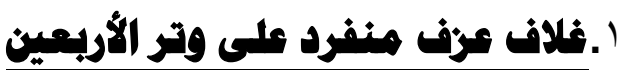

يتجه النسق السيميائي في بحثنا إلى تحليل ما أنتجه فكر الثاعر فاضل عزيز فرمان، فأصبح صوره ننظر إليها في بنية أور اق جُمعت من عناصر ألفتُ نسقاً تُنظمه مجموعة قو اعد تركيييه ميزت نفسها عن نصوص أخرى معلنة عن استقلالية انساق نصها باسم (عزف منفرد على وتر الأربعين )، وسنعرج في مقاربتنا السيميائية بخطوة الغلاف، ومـا تحمل من ثنائيات الخطى النصية عند تحليلها معتمدين مـا تشير إليهه بنية الغلاف من الفاظ، و عنوان، و ألوان، ورسـوم اسـتخدمتْ في تركيبـة بنيـة الغـلاف. فـالغلاف فضــاء سـيميائي ضـروري لوجـود مـا يجب أن بـأتي بعده مـن

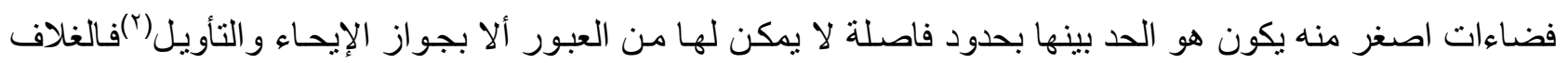

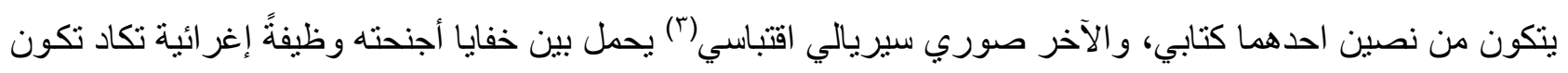


تعريفية لصاحب النص بقصدية أو غير قصدية(')، فالنص الثاني صورة سريالية لفنان كتب اسمه بخط صغير،((شـادي

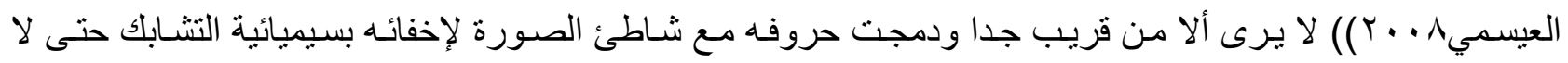

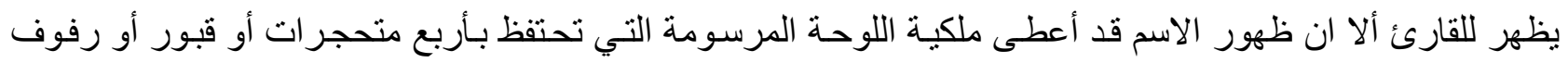

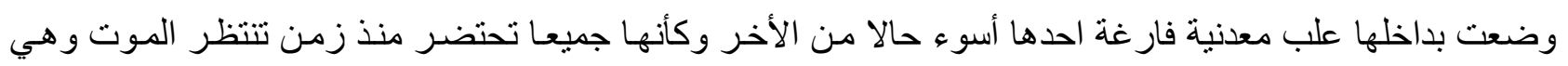

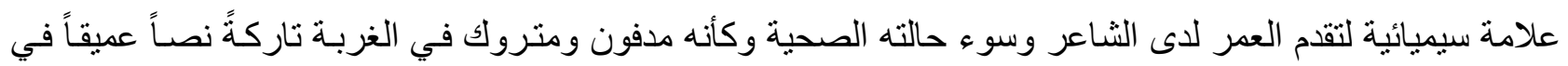
التأويل مسبور اً في معاول الغموض الضاربة في ذاكرة القارئ تاركة له الحيرة في نسق التفكير. أما النص الأول ذا النسق الكتابي فقد خط بأعلى الجهة اليمنى اسم الثـاعر (فاضل عزيز فرمـان) بخط بـارز

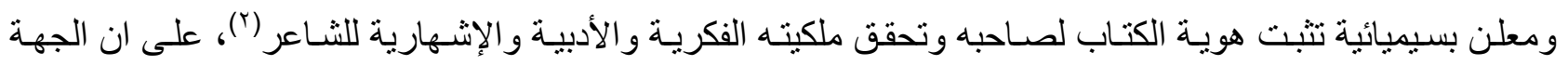
اليمنى تركتْ موازية لاسم المؤلف وهي العلامة المنتميـة لاتحساد كتاب العرب التي لا تخلو من القصدية التجاريـة في

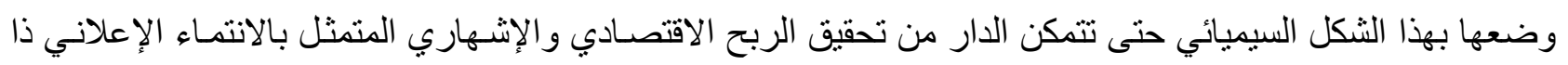
الأبِقونة الأدبية.

وينتقل البحث بسفينة التحليل حيث مرسى الحـ الفاصل بين اللوحة السـريالية والثـاطئ الواسـع المحيط بها المتكون من اللون المائل إلى الرمادي، وهذا الحد يمثل العنوان الرابط بين الحدين ( عزف منفرد على وتر الأربعين) و هو متكون من جملة اسمية (مبندأ وخبر وصفة) توسطها الجار والمجرور، على ان الجمل الاسمية تشير إلى السكون و عدمية الحركة على العكس من (الجملة الفعلية) التي تتير إلى الحركة و الانفعال، وهذا مـا يثير الغرابـة في العنوان الذي يتجه نحو السكون بعد زمن او عمر الأربعين الذي تخطاه الثاعر، مما يشير إلى سيميائية الغربـة السيرذاتية التي تحكي واقع الثـاعر الحزين .

وفي اسفل صفحة الغلاف اليسرى كتبتنْ عبارة (سلسلة الثـعر اء • (1) لتحديد جنس الكتاب في انتمائه الجنسي وتر اتييته في تعاقب الإصدار ات الطباعية، مقيدة بزمن الطباعة المكتوب أسفلها (^ . . ؟ ) لما في ذلك من تحديد الفترة التي كتبت وطبعت بها تلك النصوص حيث الظروف التي مرَّ بها الوطن الذي عاش فيه الثـاعر فكتب مجموعته الشعرية فيتسنى للقارئ معرفة الأحداث الزمنية. وينتهي الغلاف بذلك الفضاء اللوني الذي يحيط بكلا النصين الصوري و الكتابي وهو اللون المائل إلى الرمادي حيث يرمز بسيميائيته إلى عدمية الوضوح في التأويل فهو متكون من امتزاج اللون الأبيض بالأسود، وكلا اللونين يشيران إلى الضدية في معنيهها ، كضدية عمر الأربعين فلا هو شباب فيستعان بـهـ بزهو الفتوة ولا هو شيخ فيعاب عليه بتقدم العهر والدهر، وفي هذا مز اوجـة وتقارب بين سيميائية اللون الرمـادي و العنوان الصريح (عزف منفرد على ونر الأربعين) وهي التفاتة ذكية من قبل مصمم الغلاف.

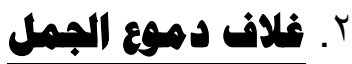

يمثل الغلاف وما مكتوب عليه الفجر الأول في حركة الذات في تنقلها من العنوان إلى العـالم وبـالعكس باعتبار هـا

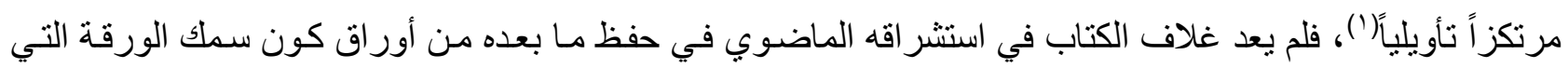
تعلن سيميائيتها الكثافية أعدت لهذا الغرض، إنما أصبح مؤو لاً سيميائياً، على ان المؤول السيميائي للغلاف ليس حراً 
في صنع او اختيار المعنى بل حريتنا في العثور عليه بأتباع الطرق الدلالية والنحويـة والتداولية المختلفة التي نستطيع ربطها بالنص عن طريق الثفرة التأويلية وبعدها يكون المعنى (؟).

إنَّ الغلاف الذي بين بدي البحث مدرك للأشياء المادية التي تنتمي إلى عالم الواقع ألا انهه ذو طبيعة خاصـة(َ) ،

فاللون الصحر اوي المتشرب بحمرة الغروب تتنمي إلى نظام سيميائي له جانب مادي بصري يوحي بصحر اء لا تحدها

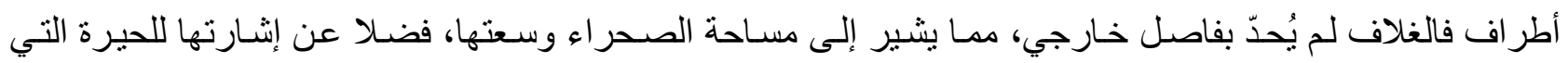
يعيشها ذللك الجمل الحزين،الذي برز رأسه في الصورة، وتخفى جسده التائه في تللك الصحر اء، فقد غاصت أرجله في أسي بحر الرمال فلم يعد يظهر ألا ذلك الر أس الباكي ذا العيون السوداء، وقد ارتسمت خمسـة قطرات من الدمع سـاقطة من عين الجمل ليؤكد في سيميائته شدة الحزن المصحوبة بالحنين حيث قد أغمض أجفانه وهو ييكي، ألا ان مـا يميز تلك لك الدموع أنها رسمت على طريقة رسوم الأطفال وبرأتهم الصادقة لكي يعبر الثناعر صدق تعابير الجمل في حزنها، وهو يمثل معادلاً موضو عياً لحزن الثـاعر وحنينه إلى الوطن الضـائع في متاهـات الصحر اء، وقد أُلجم ذلك الجمل بخيط اسود صغير كأنه إبرة من حديد أخرسته عن الكلام وفي ذلك إيحاء سيميائي عميق إلى إن الصوت البيعد غير مسموع أو انه لا يستطيع الكلام بفعل تللك الإبرة، و الخيط الأسود.

وقد مثنل الخطـان الأبيضـان المتعامـدان الذي يحمـل رأس احدهما سـنان رمـح طويـل توليد سيميائي لمعنى

مجازي(')يفسره اتجاه رأس او رقبة البعير نحوهما في إن لا عودة، أو ان هناك موت في أمل الوصول أو الحرية. ولكي نتحرر من التشفير السيميائي لواجهة الكتاب او الغلاف لابد لنـا من كثف الغموض الذبي يحول فوق

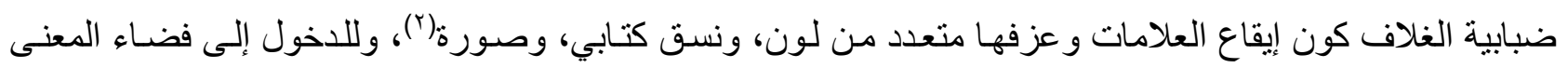

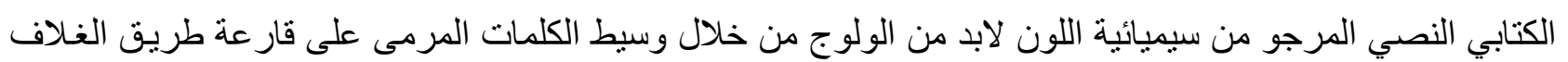
الضائع بين متاهات المساحة الثاسعة المقرونة بحجم الكتابة وبمساحة الغلاف (َ). ففي أعلى الغلاف يوجد مستطيل صغير نسبيا بلون ابيض وهو رمز السلام أو انه كفن لفَّ به اسم الثـاعر بلون اسود (فاضل عزيز فرمان) المندس في نهايته بحمرة غروب لون الغلاف الثناسع ، وقد قابله في أعلى الجهة اليسرى للغلاف أيقونة الماركة التجارية لصاحب الدار التي نشرت هذا الديو ان (اتحاد الكتاب العرب) وبمـا انها علامـة تجاريـة ربحيـة ألا أنها اخفت بين جنبيهـا تو اضـع المؤلف كونـه منتمـي إلى اتحـاد الكتـاب العرب ، وكأنـهـ أراد إخفـاء غرور الانتماء فلا تنتر الدار لمن هو لا ينتمي إليهم فعدد إلى تصغير العلامة السيميائية التجارية مع انهه وضعها بشكل بـارز

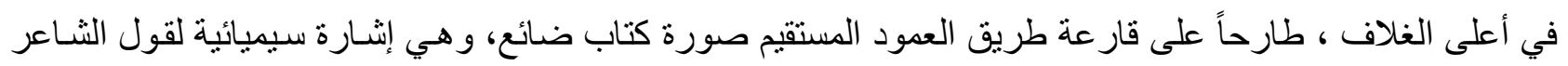
العرجي:

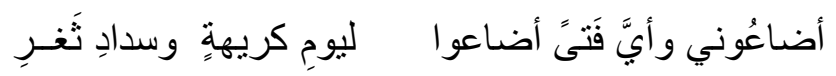

وقد وضع العنوان الرئيسي للكتاب (دموع الجمل) في وسط الغلاف بلون اسود مشـابهة لعين الجمل السوداء و هو متألف من جملة اسمية تمثل سكون الجملة النحوية كسكون الجمل في حيرته وغربته التي أبكته وهذا النص يمثل فئل

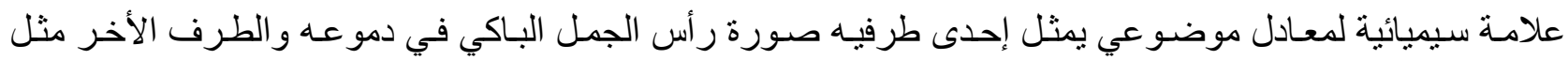


الثـاعر في حياته فهو الجمل مكتوب ومصور، وفي أسفل صفحة الغلاف البسرى كتبتنْ عبارة (سلسلة الثـعر اء ؟) لتحديد جنس الكتاب في انتمائـه الجنسـي الأدبـي وتر اتيبيتهـ في تعاقب الإصـدار ات الطباعيـة، مقيدة بزمن الطباعـة

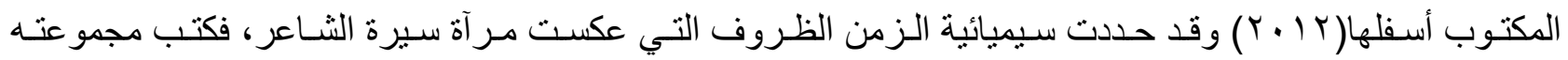
الثعرية لتكون مفتاح القارئ في معرفة الأحداث الزمنية،وقد كمنت جمالية الغلاف التي جعلت من التعبير اللغوي فيما هو نص ورسم وصورة ولون تعبيرياً سيميائياً ادبياً ').

\section{"متعى تقفته الوردة}

قد نشـاهد النص بكلتا العينين لكنتا لا نرى إلا في نظر واحد قد يتشتت أو يجتمع ، وقد تشتت نظرنـا في الرؤيـة السيميائية لغلاف الديو ان متى تتفتح الوردة، وصسورة الغلاف هي من المدرسـة الواقعية في فن الرسم، وقد قســتْ على شكل ثـلاث نصـوص لونبـة،الأولى في الأعلى وتحتوب على اسـ صـاحب المبـادرة واسـم الدار بلـون رصاصي مائل إلى الوردي الباهت، وفي الوسط مستطيل يحتوي على نص من الأزهار تحكي مر احل نموهـا، وقد تناسقت مع العنوان النصي للايوان إذ شملت وردة في طور تكوين الأوراق غير منفتحة، ووردة أخرى بدأتْ بتكوين الأور اق لكنها لم تفتح أور اقها ، ووردة أخرى منفردة الغصن تكاد ان تفتح أور اقها، و الوردة الأخيرة التي في يمين الغلاف حملت ثلاثة أغصان احتوت على صورة الأزهار الثلاثة السابقة في ثلاثة غصون مثلت أدوار حياة الوردة في تفتحها ألا أنها تركت الانفتاح الأخير للزمن فجعلت قارئ النص الصسوري يثـعر بالتفاؤل والأمل في مستقبل الغريب بان في روحه إنـر اقة السعادة المرتقبـة، وقد مثلت في سيميائيتها معـادلا موضو عيا، ذا كانت الأولى معادلا للعنوان النصي ((متى تتفتح الوردة)) و الأخرى معادلا موضو عيا لذات الثناعر ، والعنوان جملة اسمية استفهامية ساكنة بسكون

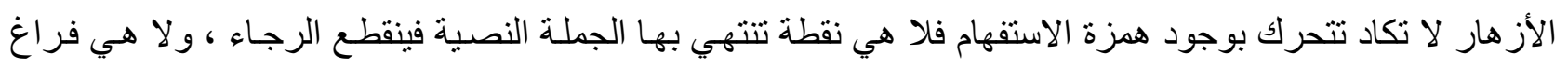
سائب يجيب عنه الزمن.اما النص الوردي الأخير فلم يوضع فيه إلا اسم الثـاعر في صحر اء واسعة الأطر اف ضـائعاً بين رمالها المتحركة فمرة يظهر و أخرى يختفي كهلال العيد بين السحاب. و أخيرا وضعت كلمة(شـعر) تحت العنوان لبيان انتماء الكتاب في جنسه الأدبي.

\section{ثالثا عتبة الإهداء}

من المعلوم أن ما من ملفوظ يقع بين دفتي منجز كتابي ما إلا وكان عتبة قرائية تتطلب الوقوف عندها ومقاربتها نقديا لمعرفة سيميائيتها و الغاية التي دفعت بالكاتب إلى توظيفها بـالتموقع المكاني لهاهو عتبـة الإهداء في المنجز الأدبي احد هذه العتبات التي تتطلب الوقوف عندها إذ إن الإهداء يمثل "عتبـة أخرى من عنبات الكتابة التي تخطط للقر اءة للوصول إلى مواطن الانفعال في النص الأدبي، فهو سهم آخر على جادة قراءة النص، وما ان تتوافر لله قراءة فاحصـة تقف في ظلاله حتى يبدأ بإغو اء وتحفيز القارئ على ممارسة توقعاته ورسم آفاق انتظار اته للمعنى الذي سيطالعه وهو في جادته هذه"(') الإهداء يختلف من كاتب إلى آخر فهو يخضع بشكل من الأشكال إلى طريقة الكاتب في الكتابـة والية اختبار اته لملفوظاته؛ لذا نجده نظام تركيب يخضع لأسس الكتابة المختلفة ، فعلى مدار الكتابـات الأدبية نجد ان العنوان يأخذ الطابع الأدبي في نسقيته، فقد يكون مفتاحا للاخول إلى شفرات النص فيكون عاملا تفاعليا من خـلال انسجامه مـع المنظومة التي يندرج ضمنها في سبيل تحقيق نوع من التداول إذ "ينفتح الميثاق المؤطر للإهداء على تحقيقات موازيـة 
تأخذ بالاعتبار السياق التداولي للنصوص كما انه ميثاق يؤكد أهمية هذه العتبة في تحديد الدلالات ومكوناتها النصية"(؟) بمعنى ان عتبة الإهداء عتبة قرائية تستلزم فهمها لفهم الغايـة التي وجهها الكاتب إلى متلقي نصـه الثـعري والتي قد تكون من اجل استمالة القارئ لقراءة النص المتن الذي يلي الإهداء بعدّها عتبـة محفزة أو مستفزة في بعض الأحيان، فهو تارة قد يكون سلسة من الملفوظات تتركب مع بعضها بعض لتتكل نصا قر ائيا وقد تكون تركيبا من لفظتين تـارة أخرى، وبالنتيجة يبقى الإهداء عتبة ونص قرائي .

وسنحاول من خـلال هذه الدراسـة الوقوف على العتبـات ( الإهدائيسة ) التي تصدرت نصـوص الثـاعر فاضل عزيز فرمان في مجاميعه الثناثة التي أخضعناها للارس و التحليل . ففي مجمو عته الأولى وقع الثـاعر إهداء مجموعته (عزف مفرد على وتر الأربعين) بنص يثـي بشكل واضـح بقصديته فيقول فيه: للحليب الذي ما تذوقت شهرا لذيذا عداه إلى حضن امي

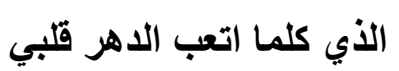
لا انتقي أي حضن سواه

لياين حرير ترى أم يدين!! يشدان قلبي الأي يتطوح في سفح العمر نحو ذراه إلى امرأة شكلها شكل

(1)!!

ثمة علاقة واضحة بين الإهداء كعتبة وحجم النص الذي يندرج تحت كلمة ( الإهداء ) فهو مؤشر يرشد المتلقي إلى نوعية العلاقة الرابطة بين الأم المهدى لها وولدها الثناعر الذي أهدى إليها مشاعره وهو يكثثف عن مستوى الدعم

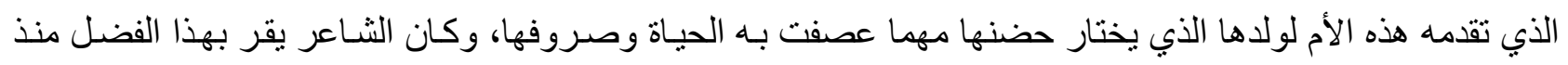
و لادته التي لا يعي عنها أدنى شيء فكانت دلالة الحليب الموصوف بالثهد كاثتفة عن هذه العلاقة التي أراد الثـاعر 
الوقوف عندها مليا لتكون أول ما يثير ذائقة المتلقي وتستهويه لعظمة الأم ومكانتها عند البشر جميعا فهذا النوع من العتبات له فاعلية في خلق صور ذهنية لنخصية المهدى له إذ إن الثخصية "نظاما ينشئه النص تدريجيا لكنها لا تعدم في بداية ظهور ها هوية عامة فهي في البداية شكل أو بنية عامة وكلمـا أضيف إليها خصـائص أضحت معقدة مر غوبـة من دون ان تفقد هويتها الأصلية"(r).

ثم ينعطف بالإهداء من هذه المرحلة التي لا يعي عنها شي ويقر بفضلها ينتقل بـالمتلقي إلى مرحلـة يعيها تمامـا و هي مرحلة كبره و ألام لا تز ال بذلك العطاء السخي وحرق سنين عمر هـا من اجل إضـاءة حياة الابن، فيوصف يديها بالحرير رغم تعبها وتقدم العمر بها فيقدم هذا المنجز الثعري بكل ما يحمل من مشاعر لام شكلها شكل ألاهو التعب لمـا قدمت وتقدم ، فالعلاقة بعد كل هذا تبدو واضحة بين العنوان الرئيس وهذا الإهداء الذي جاء جزءا من العزف المفرد الأربعيني للشاعر .

أمّا المجموعة الثانية من بين مجاميعه الثعرية الثناث(دموع الجمل) فقد اختار الإهداء المكثف بتوقيع يقول فيه:

إلى الواحة الخضراء التي كفكفت دموع الثاعر الجمل

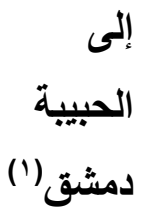

يخص الثاعر بهذا الإهداء الموجز دمشق ويصفها بالواحة الخضر اء التي كفكفت دمو عه، فالفضل الذي يقر بـه دمشق جعله يخصها بإهداء جزء من مشـاعره الإنسانية المتمثلة بالمجموعة الثـعرية (دموع الجمل) وييدو من خـلال ارتبـاط دلالـة الدموع المكفكفة ان الثـاعر كان مثقلا بـالهم والحزن وقد وجد مـلاذه الآمن في سوريا التي احتضنت العر اقيين في فترة زمنية مرت بالبلا فالجمل علامة رامزة إلى الصبر و التحمل، فاي حمل ناء بهذا الجمل الذي اضطره للسفر إلى دمشق لتكفكف دمعهه وتجلي همه.وقد تضافرت عنبة الإهداء مع سيرورة ومضمون الدلالة الكلية التي تشي بالحركة الانفعاليـة التي تدفع بالذات الثـاعرة إلى الاستجابة لضـغوط الحالة النفسية ومـا تثـعر بـه إزاء المهدى إليه، فالإهداء (وسيلة إيحاء وتأويل تدفع القارئ إلى تخيل حقيقة شخصية المهدى إليه، و العلاقة التي تربطه بالثـاعر،

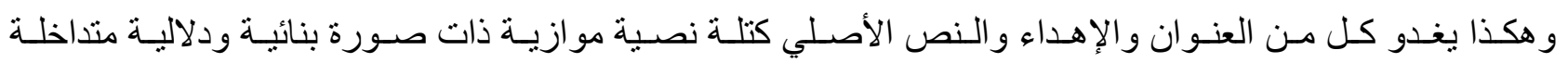
ومنتـابكة"(؟). ومن غير الممكن تخطي هذه العتبة عند قر اءة منجز ما، فحقق الإهداء كعتبـة تجسيدا للرؤيـة التي تؤطر نصوص المجمو عة عبر شرو عها بتقديم السبيية للإهداء. الإهداء الثالث ضمن مجمو عته الثُعرية (منى تتقتح الوردة) الصادر عن المؤسسة الوطنية للتنمية والتطور لسنة

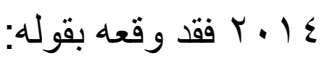
إلى.. والدي والى روحه حيث نام حزين 


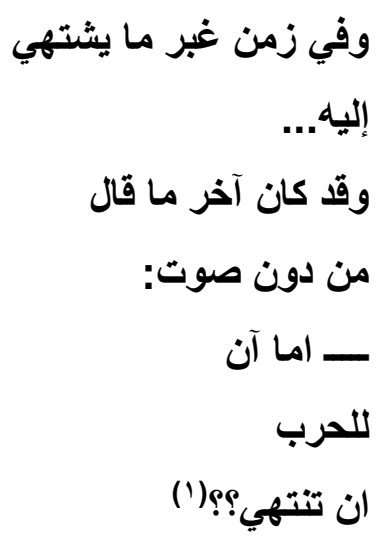

دأب الثناعر فاضل عزيز فرمـان على اختيار الإهداء الملائم لمجاميعه الثـعرية لكونها من العتبات التي

تو اجه القارئ أول العمل الأدبي فهي موجه قرائي ومن أهم العتبات القرائية التي تتطلب من المبدع ان يكون مستعدا فيها لمو اجهة متلقيه، فلكونها بداية العمل فيشترط فيها ان تكون "محكمة البناء تثند القارئ إلى النص وتجعله يتابعـه إلى دي النهاية ، و على عكس ذلك فإن البداية الرديئة حتى و إن كانت بقية النص جيدة ، فإنها تجعل القارئ يعزف عن النص وتصـرفه عنـه ؛ ليتفـادى المسـار النصـي الثـاق"(؟)، فوقـع اختيـار الثــاعر علـى الأب ليكـون هـو العتبـة الإهدائيـة لخصوصية الأب ومكانته في ذهانية ولده وقد سيق الإهداء في مساق أدبي خيم عليه الحزن وكانت علامـة ( الحذف ) بين إلى ... و الدي تستو عب دلالات سيميائية للقارئ ان يضع ما يشاء لسد الفجوة التي خلفها هذا الحذف، ومع الدخول في عو الم نص الإهداء نجده معادلا موضو عيا لهموم مجتمع ينتظر انتهاء حرب خلفت الهم و الحزن وأخذت مـن منـه

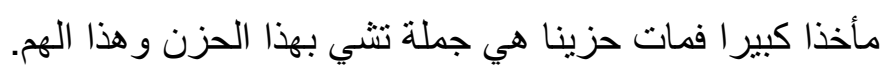

رابعا عتبة التصدير

تمثل عتبـة التصدير في المؤلفـات الكتابيـة احد العتبـات المهـة لكونها تقوم "في توجيه سـهم القراءة نحو متن النص، و هي مفتاح لانها تمثل شفرة بيولوجية في النص تجتهد تكثيفا لتختزل وتهيكل مر احل نمو أعضـاء الكتابـة داخل

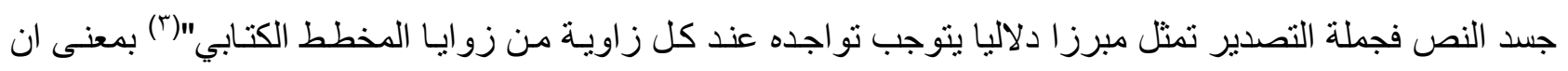
التصدير هو إقرار من قبل الكاتب بطبيعة المنن النصي الذي يلي تصديره، فيكون بمثابـة خريطة بيتعين بها المتلقي نئي للاخول إلى عو الم المنن النصي. وسنحاول مقاربة العتبات التي تصدرت نصوص الثناعر فاضل عزيز فرمـان بغية الوصول إلى فاعليتها على

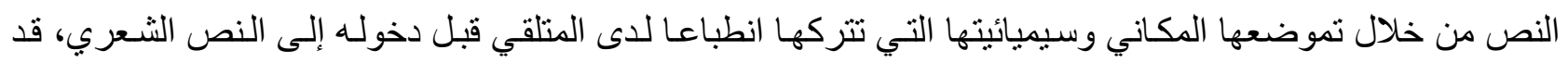
وردت هذه العتبات بقسميها الذاتي و الغيري بحسب حاجة النص لهذا التوظيف، ومن هذه العتبـة ( التصدير الذاتي) مـا جاء مع مجمو عته الثعرية متى تتفتح الوردة فيقول بعدما سماه مدخل ثناني: في هذا الكون الواسع الجميل... الحرب هي الاستثناء والسلام هو القاعدة 


\section{من صنع هذا الاستثناء

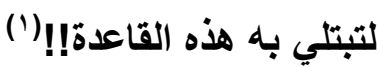

يمثل هذا التصـدير البوصـلة التي ترشـد المتلقي إلى دلالـة نصـوص المجموعـة الثـعرية بالكامـل فنصـوص المجموعة تعالج ثيمة الحرب و عالمها العنيف عبر إجر اء ثمة مقارنـة بين الحرب والسـلام وحـال الإنسـان فيهما، فكان التصدير يرسم لوحة فنية كبيرة يعالجها بمسحة فلسفية تقر بان الإنسـان مخلوق سـام وهي صفة التي خلقه الله عليها، وما عكس هذه الصفة فهي استثناء الاستثناء الذي يصنعه الإنسان ذاته، فكانت هذه القاعدة الفلسفية تتعاضد مع مضمون هذه النصوص التي انتظمت بنسق معارض لفكرة الحرب، فكانت علامة التعجب التي ختم بها النص موقف الثاعر من

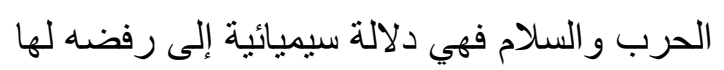

أمّا التصدير الغيري فقد جاء ضمن مجموعة متى تتفتح الوردة وتمثل هذا التصدير بـ قصيدة شعبية للثـاعر

$$
\text { مظفر النواب يقول فيها: }
$$

مثل بلبل

\section{كعد غبشه وشاف بغداد الحبيبة}

\section{بلاية تين(r)}

في هذا التصدير الغيري للمجموعة المبنية بناء مفارقي خالف فيه الثناعر المساق النصي الذي انبت على أساسـهـ نصوص المجموعة التي تلي من حيث الترتيب هذا التصدير مما ولد علامة قر ائية تتطلب الوقوف عندها فالتصدير هنا كتب بأسلوب كتابة النص الثـعري الثـبي وهو يختلف من حيث جنس الكتابـة التي عليها نصوص المجموعة فكان تصدير ا صادما، في بناءه مما يدفع المتلقي إلى البحث عن سبب هذا التصدير، لكن دلالة الملفوظات السيميائية تثـي بالتكثيف العالي الذي يختزل نصوص المجموعة بالكامل فعلاقة البلبل بالتين علاقة تكثف عن تلازمهمها، فقدان البلبل للتين معدلا موضوعيا لفقدان بغداد مكانتها وأمنها وسلامها فبغداد مدينة السلام هي صفة لازمتها على مر العصور. وفي مجموعته الثعرية (دموع الجمل) صدَّر الثاعر مجموعته بييت للثاعر دعبل الخزاعي الذي يقول فيه:

عين افتي لافتح عيني كثير


يتصدر بيت للثاعر دعبل الخز اعي مجموعة دموع الجمل وقد جاء مكتوبا بطريقة تجعله يغادر نظامه الثكلي ( نظام الثطرين) ليركبه باسلوب مغاير له، مما خلق حالة من الصر اع النفسي المتولدة من حالة الثـك و الاختلاف بين

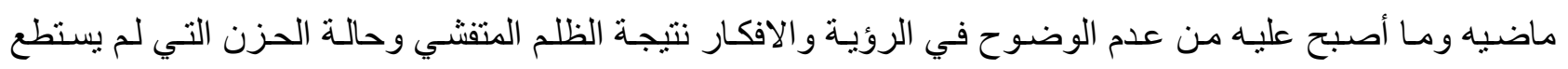
مجار اتها، فكان هذا التصدير منماهيا مع إحساسات الثناعر وهو تصدير يخلق حالة من التشويق فقد كان هذا التصدير محايثا لنصوص المجموعة وعتبة قر ائية موجه لفعل التلقي للمتن النصي الذي سبقه التصدير في التموضع المكاني فهو عتبة ذات وظيفة افهامية اثثت لمضمون النصوص الثعرية التي سيتلقها القارئ.

اتضـح من خـلال قر اءة المجاميع الثـعرية ومقاربتها نقديا وفق المنهج السيميائي اتضـح ان الثـاعر حساول

الخاتمة: استثمار كل العتبات التي تمكنه من ايصال نصه الثعري إلى متلقيه باسلوب تتضـافر فيه الكلمـة الثـعرية بوصفها البنيـة

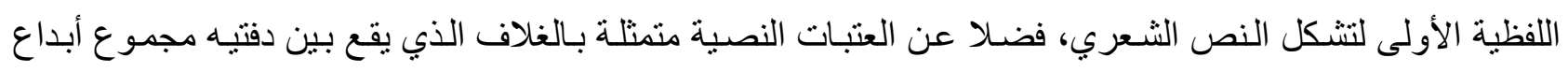
الثـاعر ومرورا بعتبـة العنوان الرئيس لكل مجموعـة فهو المفتـاح الاول الذي يفتح سبل الدخول إلى عو الم النص، مرور ا بالعنوانات الفرعيـة التـي تكون بتمـاس مبانشر مـع العنوان الرئيس، و اتضـح ان لعتبـة التصدير و الإهداء اهميـة بالغة في بيان الوجهة الدلالية التي يتجهها الثـاعر في مجموعته الثـعرية والغايـة التي يود ان تكون نصوصسه منسـاقة بسياقه، وقد كان لكل عنبة من هذه العتبات دلالة كثفت عنها الدر اسة السيميائية.

$$
\begin{aligned}
& \text { (1) عتبات النص الأدبي، حميد لحمداني، علامات،ع أ، س r . . r: rr. }
\end{aligned}
$$

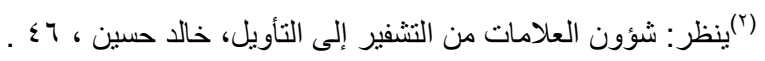

$$
\begin{aligned}
& \text { (") }
\end{aligned}
$$

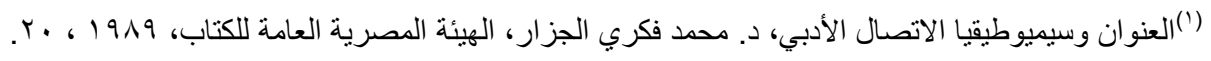

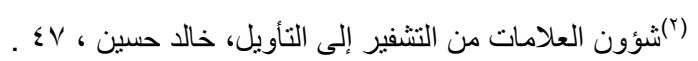

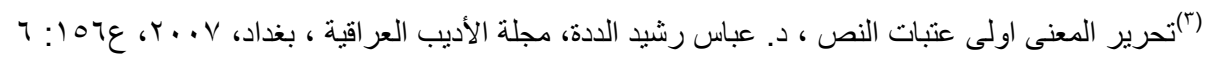

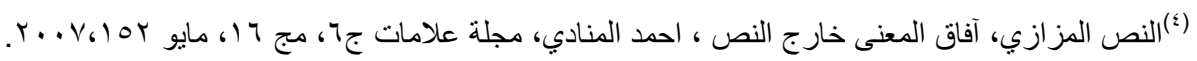
(0)

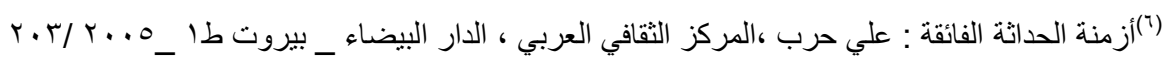

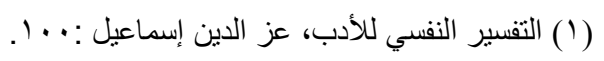

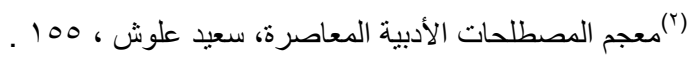

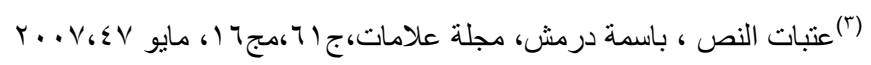

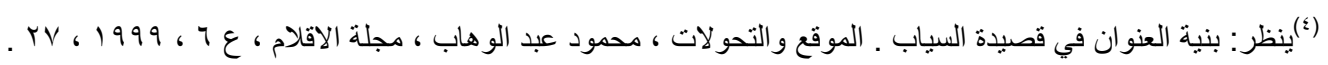

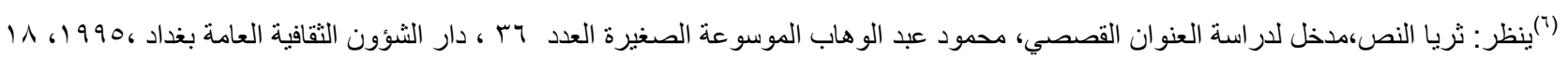

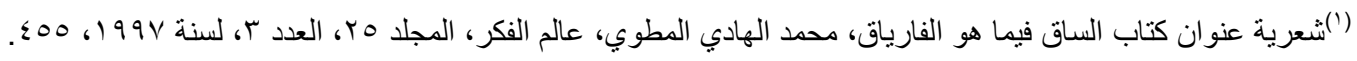

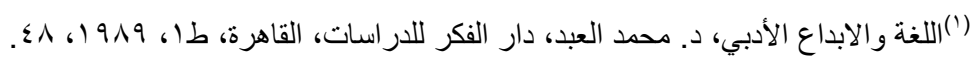

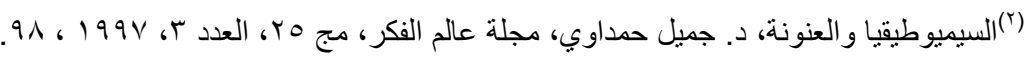

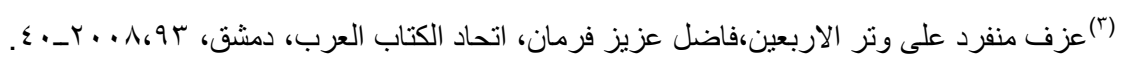

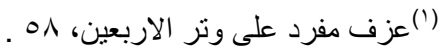

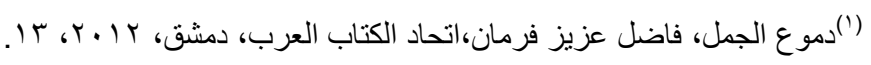




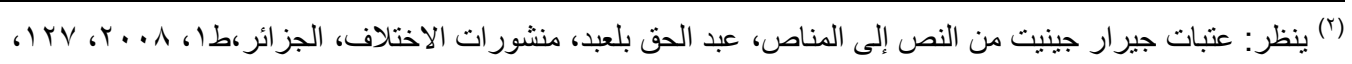

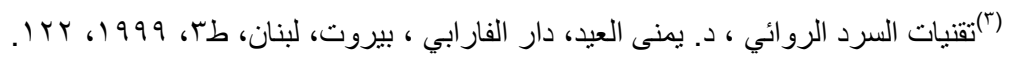

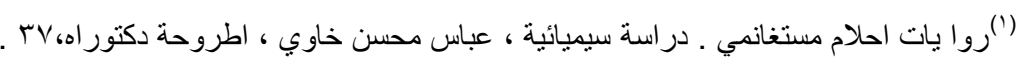

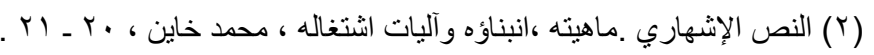
(r)

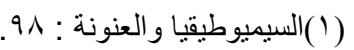

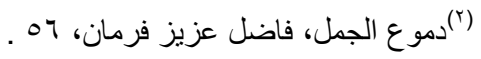

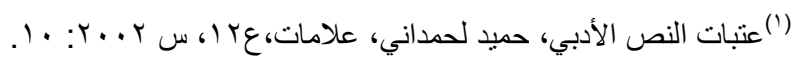
(r) (r)

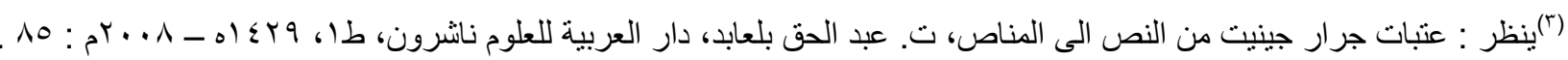

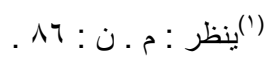

$$
\begin{aligned}
& \text { () (r) }
\end{aligned}
$$

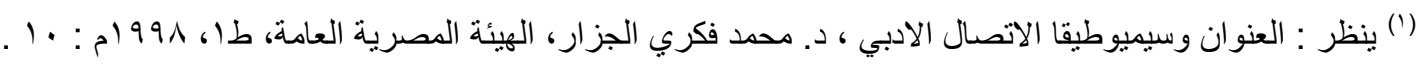

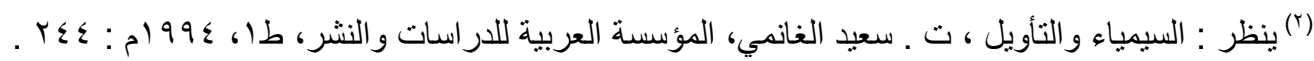

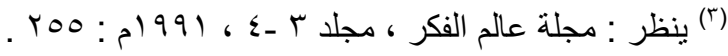

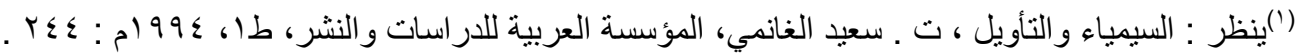

$$
\text { . } 0 \text {. }
$$$$
\text { (r) }
$$

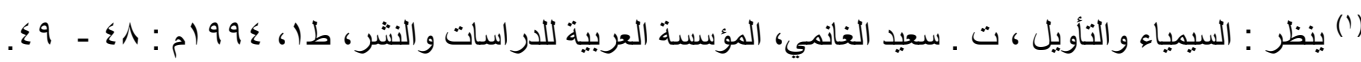

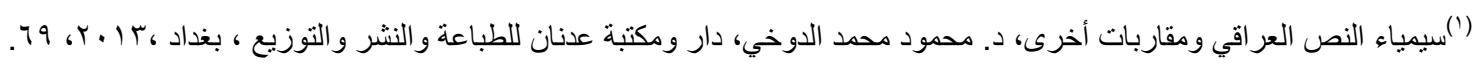

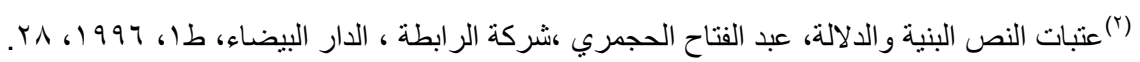

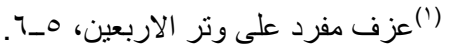

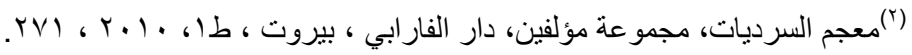

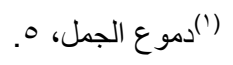

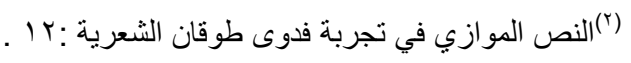

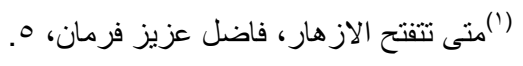

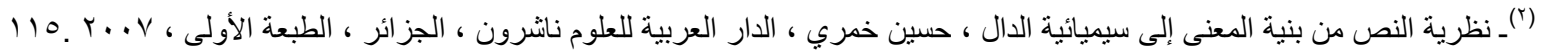

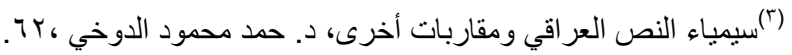

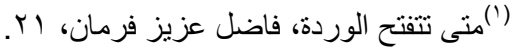

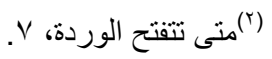

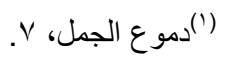

المسادر والمراجع:

أزمنة الحداثة الفائقة : علي حرب ،المركز الثقافي العربي ، الدار البيضاء _ بيروت طا ـ ـ. . . . . بنية العنوان في قصيدة السياب ـ الموقع والتحو لات ، محمود عبد الوهاب ، مجلة الاقلام ،ع 7، 1999 . تحرير المعنى اولى عتبات النص ، د. عباس رشيد الددة، مجلة الأديب العر اقية ، بغداد، V . . Y، ع70 10

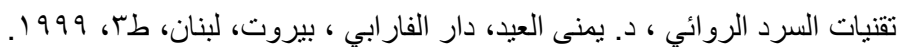

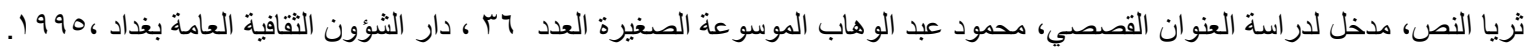

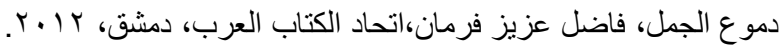




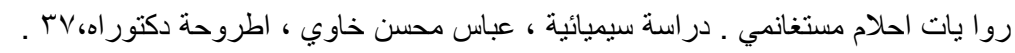

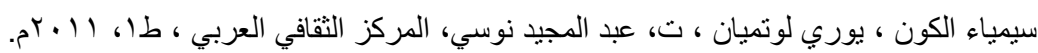

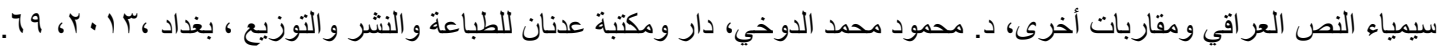

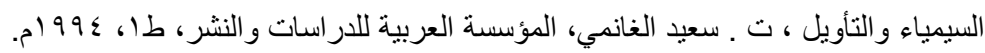

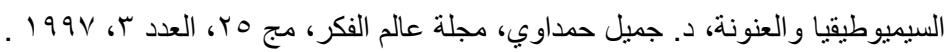

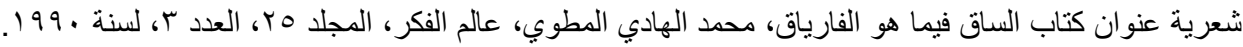

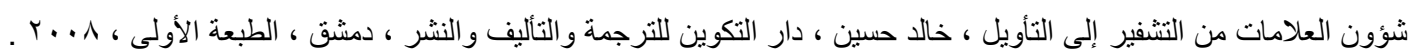

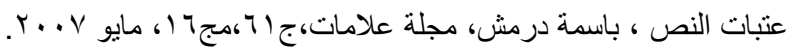

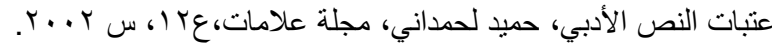

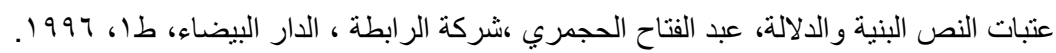

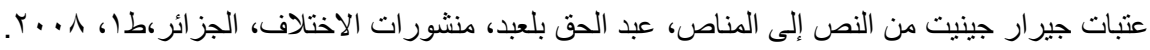

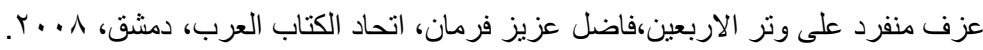

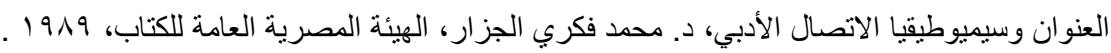

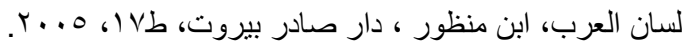

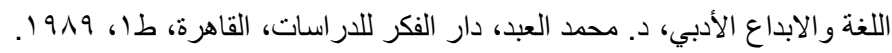

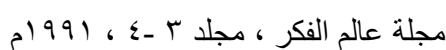

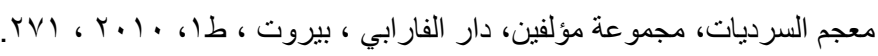

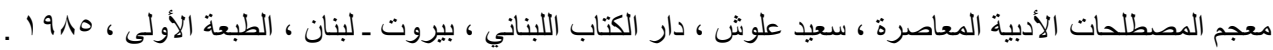

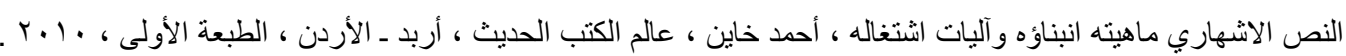

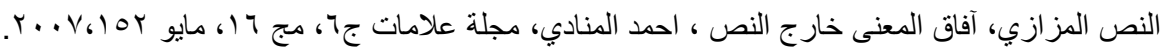

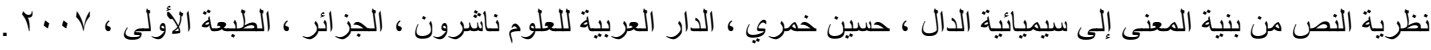

